جامعـة نيويورك أبـوظـبي 亗 NYU |ABU DHABI

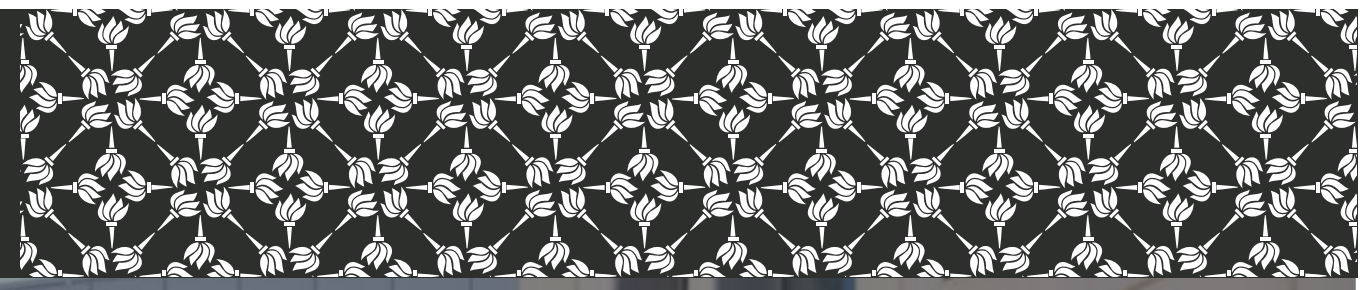

\title{
Emirati women do not shy away from competition: Evidence from a patriarchal society in transition
}

\author{
Aurelie Dariel, Curtis Kephart, \\ Nikos Nikiforakis and Christina Zenker
}

Working Paper \# 0011

November 2017 


\title{
Emirati women do not shy away from competition: Evidence from a patriarchal society in transition*
}

\author{
Aurelie Dariel $^{\mathrm{a}}$, Curtis Kephart ${ }^{\mathrm{a}}$, Nikos Nikiforakis ${ }^{\mathrm{a}}$ and Christina Zenker ${ }^{\mathrm{b}}$
}

This version: November 6, 2017

\begin{abstract}
We explore gender attitudes towards competition in the United Arab Emirates - a traditionally patriarchal society which in recent times has adopted numerous policies to empower women and promote their role in the labor force. The experimental treatments vary whether individuals compete in single-sex or mixed-sex groups. In contrast to previous studies, women in our sample are not less willing to compete than men. In fact, once we control for individual performance, Emirati women are more likely to select into competition. Our analysis shows that neither women nor men shy away from competition, and both compete more than what would be optimal in monetary terms as the fraction of men in their group increases. We offer a detailed survey of the literature and discuss possible reasons for the lack of gender differences in our experiment.
\end{abstract}

Keywords: gender, competition, culture, institutions

JEL Codes: C70, C91, J16, J24, J31, M52

\footnotetext{
${ }^{a}$ Division of Social Science, New York University Abu Dhabi, P.O. Box 129188, Abu Dhabi, United Arab Emirates. Email: apd5@nyu.edu, curtis.kephart@nyu.edu,nikos.nikiforakis@nyu.edu.

${ }^{\mathrm{b}}$ College of Business, Zayed University, P.O. Box 144534, Abu Dhabi, United Arab Emirates. . Email: christina.zenker@,zu.ac.ae
}

\footnotetext{
* We would like to thank the Guest Editor, two anonymous reviewers, and Bob Slonim for valuable comments, Loukas Balafoutas and Ernesto Reuben for valuable discussions, as well as faculty members at Zayed University who gave us their classes to run our experiment. All aspects of the experiment were approved by the IRB at NYU Abu Dhabi (\#024-2016) and Zayed University (\#ZU16_013_F).
} 


\section{Introduction}

The reasons for the gender differences in outcomes in labor markets across the world have been a topic of continuous debate. Recent evidence suggests that a contributing factor is the different attitudes men and women have towards competition. In a pioneering study, Niederle and Vesterlund (2007, henceforth, NV) introduced a new experimental paradigm and found that, even when women perform as well as men, men were more than twice as likely to select into competition. Several subsequent studies have confirmed the tendency of women to shy away from competition, and of men to compete too much. As can be seen in Table A1, across all studies with university students, there is not a single instance in which women were found to be more likely to select into competition than men. ${ }^{1}$ Perhaps as important, the elicited willingness to compete correlates with educational and occupational choices (Buser et al. 2014, Buser et al. 2017, Reuben et al. 2015, Reuben et al. 2017).

One reason that has been suggested for the observed gender differences in the willingness to compete is culture. Gneezy et al. (2009) find that, while men are roughly twice as likely to select into competition in a patriarchal society in Tanzania, women are more likely to compete in a comparable matrilineal society in India. Similarly, Andersen et al. (2013) find that boys aged between 7 and 15 are more likely to compete than girls in patriarchal but not matrilineal villages in India. ${ }^{2}$ Taken together, this evidence suggests that comparing gender attitudes towards competition in different cultures is not only interesting, but also potentially important for designing effective policies to reduce gender differences in labor markets.

We present evidence from an experiment studying attitudes towards competition among young nationals in the United Arab Emirates (UAE). The UAE is probably best known internationally for its remarkable transformation in a short time period; one of the wealthiest countries in the world today, half-a-century ago, prior to the discovery of vast oil reserves in 1959, the local population was living in poverty (Al Fahim 2011). For our purposes, however, the UAE is interesting for another reason. The UAE is what some sociologists refer to as a "patriarchal society in transition" (Moghadam 2004). Although historically a traditional

\footnotetext{
${ }^{1}$ Across all university-student samples in Table A1, women select to compete $31 \%$ of the time and men $56 \%$ (unweighted average). The gap appears to be smaller in non-university samples, particularly among pre-university students and children (women: 37\%; men: 47\%), where there are also instances in which women are found to compete more often than men (see Panel C in Table A1). For a discussion of the key findings in this literature, see Niederle (2016).

${ }^{2}$ Using the NV paradigm to study the willingness of children aged 3 to 18 -year-old to compete in three different tasks, Sutter and Glätzle-Rützler (2015) find evidence that the gender-gap in competitiveness emerges early in life - in some cases from the age of 5 - and persists. Panel C in Table A1 reviews studies using exclusively children and pre-university teenagers.
} 
patriarchal society, in the past decade, the government has introduced one policy after another aimed at empowering women and reducing the substantial gap between men and women (UAE overall rank: 124 out of 144; for comparison, USA overall rank: 45 out of 144; World Economic Forum 2016, henceforth WEF).

The traditionally patriarchal values were cited in a recent survey (Pennington 2016) as the main reason why the relative participation of Emirati women in the labor force is low (42 vs. 92\% for men; UAE rank: 128 out of 144; USA rank: 56 out of 144; WEF). The UAE government has attempted to overcome some of the social constraints local women face in the labor force by adopting a number of targeted policies. Examples include the mandatory membership of Emirati women in the Boards of Directors of federal bodies, companies and institutions, and the establishment of the UAE Gender Balance Council charged with promoting equality and opportunities for women in the labor market (UAE Government 2017). And indeed things appear to be changing; 9 of the 28 ministers in the UAE government are currently women; women's political empowerment as measured by WEF has increased by a factor of nearly 10 within a decade, increasing considerably the UAE's global standing (UAE rank in 2006: 112 out of 115 countries; UAE rank in 2016: 83 out of 144 in 2016; USA rank in 2016: 73 out of 144); the wage gap between men and women after controlling for occupation is now one of the smallest in the world (UAE rank: 8 out of 144; USA rank: 66 out of 144).

The extent of the tension between centuries-old patriarchal values and modern institutions concerning the role of women in labor markets is what makes the UAE an interesting population to study. ${ }^{3}$ Our sample consists of Emirati nationals, young adults who were kids when some of the early policies targeted towards empowering women were introduced (mean age $=22.5$, st. dev. $=1.6$ ). ${ }^{4}$ If attitudes towards competition (as measured using the NV paradigm) are shaped by culture, then, if the recent institutional changes have been ineffective at affecting these attitudes, we would expect at least as large a difference in the willingness to compete between Emirati men and women as that in Western samples, ceteris paribus. If we observe smaller or no differences in gender attitudes, this could be taken as evidence for the effectiveness of these policies for empowering women. Having said this, our experiment will not allow us to distinguish the impact of these policies from that of other factors that could affect the willingness to compete. We return to this topic in the conclusion.

\footnotetext{
${ }^{3}$ See also Khachatryan et al. (2015) who compare the competitiveness of boys and girls in Armenia - a society which since the collapse of communism has been experiencing a slow return to patriarchal values.

${ }^{4}$ For example, $65.3 \%$ of individuals in our sample report that their mother never had a job outside home after giving birth.
} 
We explore attitudes towards competition in both single-sex and mixed-sex groups. In a society like the UAE, where social forces sometimes prevent women from interacting in public with men outside their families, an increase in women's participation in the labor force raises another interesting question: how do attitudes towards competition depend on the gender of the other competitors? Are women less willing to compete against men than they are to compete against other women? Most previous studies on attitudes towards competition have considered competition in mixed groups exclusively. Two exceptions are Datta Gupta et al. (2013) who find that men tend to compete less against other men in certain treatments (no effect for women), and Sutter and Glätzle-Rützler (2015) who find no overall differences in behavior. ${ }^{5}$

\section{The experiment}

\subsection{Sample selection and experimental procedures}

Studying the behavior of Emiratis in a laboratory poses challenges. Emirati nationals are a minority in the UAE (e.g., according to Statistics Centre Abu Dhabi, in mid-2016, Emiratis were $18.9 \%$ of the Emirate's population), implying that without targeted recruitment one would need a large sample to have a sufficient number of observations. Furthermore, Emiratis tend to be wealthy, hence, the usual monetary compensation can be insufficient to motivate many of them to sign up for an experiment. The challenge is even greater when it comes to recruiting Emirati women whose daily activities are sometimes regulated by their families. Even if a minority of women is limited, this could introduce bias in our estimates. ${ }^{6}$

To overcome these problems and reduce the problem of selection bias, we decided to conduct classroom experiments at Zayed University - the largest public university in the nation's capital. The majority of students $(85.6 \%)$ are female, while the student body consists almost exclusively of Emirati nationals (97\%). The campus is divided in two; one sub-campus

\footnotetext{
${ }^{5}$ Related to this, Gneezy et al. (2009) control for beliefs about gender composition in regressions and find some evidence suggesting that the probability of choosing the competitive option decreases for both men and women in both samples as the proportion of men in a group increases. The data in Balafoutas and Sutter (2012) also speaks to this issue as they allow (among other) for quotas. This implies that, for some positions, women compete against women, and men against men. Balafoutas and Sutter (2012) find quotas increase the willingness of women to compete, which could be interpreted as evidence women compete more in single-sex groups. See also Niederle et al. (2013) who also ask subjects' beliefs and find men to be significantly more confident than women in mixedsex groups, but not in single-sex groups.

${ }^{6}$ Almås et al. (2016) provide evidence that children from high socioeconomic status (SES) are more willing to compete than children from medium or low SES families. In high and medium SES families, girls are considerably less willing to compete than boys. In contrast, in low SES families, girls are as likely to compete as boys.
} 
for women and one for men. While undergraduate students in a given class are always of the same sex, instructors often are of the opposite sex. ${ }^{7}$

The experiment was conducted in February and March of 2017. ${ }^{8}$ We asked professors teaching upper-division courses (i.e. students in the two final years of college) to allow us to run our experiment in their class without providing them with details about the experiment, our research questions or any monetary incentives. ${ }^{9}$ The classes of professors who agreed to help us were randomly assigned to one of four treatments described below.

Students were not informed that an experiment would take place in their class. One day before the experiment, they were informed via email from their professor that there will be a "special activity" during class and were simply asked to bring their laptop (though we brought several extra laptops for forgetful students). Once students arrived in class, they were asked to sit far away from each other and connect to o-Tree (Chen et al 2016). During the one hour of the experiment (i.e., as long as the duration of the class), professors were not permitted in the classroom. The experiment was run by three experimenters ( 1 male and 2 female) who alternated in reading aloud the instructions (for details, see OSM).

\subsection{Experimental design}

Our experiment is built on the paradigm introduced by Niederle and Vesterlund (2007, $\mathrm{NV}$ ). Each session consists of 3 experimental tasks, one of which is randomly selected for payment at the end of the third task. In each task, participants are asked to add up a series of two-digit numbers for 3 minutes. The tasks differ in how performance translates into earnings. In the first task, participants are paid for each correct answer using a piece rate of 2 AED (approximately $0.55 \mathrm{USD}$ ). In the second task, each participant competes in a tournament against three other randomly selected anonymous students. If s/he correctly solves the highest number of additions s/he receives 8 AED per correct answer. The rest of the group receives nothing. Ties for the first place are randomly broken. Finally, in the third task, participants must choose between the piece rate and the tournament. After that, they perform the task one

\footnotetext{
${ }^{7}$ The evidence on the impact of single- vs. mixed-sex schooling on competitiveness is mixed. One study finds no differences in competitiveness (Lee et al., 2014), and the other finds girls compete more in single- than in mixedsex schools (Booth and Nolen, 2012).

${ }^{8}$ To ensure that there are no spill overs across sessions that may be driving our findings, we repeated our analysis focusing on sessions that took place in the first three days of our experiment. Our conclusions are unaffected. Throughout the paper, we control for 'session effects' in our regression analysis.

${ }^{9}$ This project is part of a larger one on the effect of motherhood on the willingness to compete. Here, we report data only from treatments for which we have observations for both men and women, excluding observations from mothers and pregnant women. In total, we report data from 20 different classes with 18.6 students on average.
} 
final time. Like in NV, if they choose to compete, their score is compared to that of participants in the second task (for details, see OSM).

The last task measures individuals' attitudes towards competition. All else equal, a riskneutral participant who only cares about maximizing her monetary earnings is indifferent between the two incentive schemes when the chance of winning the tournament is $25 \%$ (i.e., when she thinks she is as likely as others to win the competition). To help us understand the determinants of individual choices, we wanted to obtain measures of individual beliefs and risk attitudes. As we only had one hour to set up the experiment, read instructions, have subjects play the experiment, fill out a post-experiment questionnaire and pay them, we decided to simply ask students at the end of the third task if they thought the other individuals in their group would solve on average more or fewer additions correctly in Task 2 than they did, without providing monetary incentives. Concerning risk attitudes, we asked students in a postquestionnaire if they thought they were generally a person who tries to avoid taking risks. ${ }^{10}$

We examine behavior in single-sex and mixed-sex groups. At the start of task 2, participants are clearly informed whether they will be competing only with other people of the same gender or in mixed groups. Participants are only informed about their individual score in each task. Subjects received detailed feedback (incl. which task was selected for payment and their earnings) after task 3 and, in particular, after they stated their belief about the performance of others in task $2 .{ }^{11}$ Following this decision and after participants answer a postexperiment questionnaire, they were paid privately outside the class. On average, participants earned 65.20 AED (17.75 USD).

\subsection{Power calculations and sample size}

Our sample consists of 147 students. Of the 66 men, 30 were allocated in the single-sex condition and 36 in the mixed-sex. Of the 81 women, 35 and 46 were allocated in the singleand mixed-sex condition, respectively. Using the data of $\mathrm{NV}$ as a basis for power calculations and pooling across single- and mixed-sex groups, our sample size will allow us to detect gender differences in the willingness to compete at the $5 \%$ level, $99.8 \%$ of the time. If we instead take as benchmark the (unweighted) average across all studies using university students

\footnotetext{
${ }^{10}$ Responses to this question have been shown to be robust and stable over time (Dohmen et al. 2011, Lönnqvist et al. 2015). Note that, apart from time restrictions, we could not use the usual lotteries for eliciting risk preferences as gambling is forbidden in Islam.

${ }^{11}$ After students were informed about their individual earnings, they were given the option to give a fraction of their earnings to charity. Given space constraints, we do not discuss this part of our experiment here. In summary, we find that individuals selecting to compete are as likely to make a donation as those choosing the piece rate; we find no differences in giving between men and women.
} 
in Table A1, women selected the tournament $31 \%$ and men $56 \%$ of the time. Our sample will allow us to detect such difference at the $5 \%$ level $87 \%$ of the time. If $31 \%$ women select into competition, we will be able to detect a difference $80 \%$ of the time at the $5 \%$ level with our sample so long as men are 22.9 percentage points more likely to compete (i.e., at least $53.9 \%$ choose tournament).

For evaluating the impact of varying the composition of groups, we use the data in Datta Gupta et al. (2013) as a basis for our power calculations. Although women in their sample are as likely to compete against another woman as they are to compete against a man $(25 \%$ in both cases), men are more likely to compete against a woman (62.5\%) than against another man (33.3\%). With our sample of 66 men, we would be able to detect a similar difference at the 5\% level, $94.8 \%$ of the time. All tests reported in the paper are two-tailed.

\section{Experimental results}

Result 1: Overall, women are not less likely than men to compete. Controlling for performance, however, women are more likely to compete in the tournament than men. The difference is driven by choices in single-sex groups.

SUPPORT: Across conditions, women select the tournament scheme $54.3 \%$ of the time, while men $50.0 \%$. The difference is small and not statistically significant ( $p$-value $=0.996, \chi^{2}$ test, $N=147$ ). Women, however, do not perform as well as men in the addition task. Across singleand mixed-sex groups, they solve correctly $26.5 \%$ fewer addition problems than men in the first task ( 11.17 vs. 15.20 ; $p$-value $<0.001$, MWU test, $N=147), 27.6 \%$ fewer in the second task (11.80 vs. $16.30 ; p$-value $<0.001)$, and $17.9 \%$ fewer in the third task (13.27 vs. $16.19 ; p$ value $<0.001$, ). To take into account the differences in performance and other factors that may affect the willingness to compete, in Table 1 we present the results from a probit regression on the decision to enter into competition in Task 3. The regression analysis follows that in NV (see Table VI) controlling for individual performance in the second task (Tournament score), the change in performance between the first and second task (Tournament - Piece rate score), beliefs about the average performance of others (Guess other's score), self-reported risk attitudes (Risk tolerance), the composition of groups (Single-sex group) as well as the potential interdependency within experimental sessions. Model (1) indicates that once we control for these factors women are nearly 17 percentage points more likely to select into competition than 
men, across conditions $(p$-value $=0.036) .{ }^{12}$ Model $(2)$ shows that women compete significantly more than men in single-sex, but not in mixed-sex groups (model 3).

Although women are not less likely to compete than men in our sample, it is worth noting that the determinants of selecting into competition are otherwise similar to that in previous studies. As seen in columns (1)-(3), individuals who expect others to have performed better than them on average, are less likely to select into competition; individuals scoring higher in the tournament in the second task are more likely to choose to compete. Using a probit regression with "Guess other's score" as the dependent variable and the first three regressors from model (1) in Table 1, we find no significant difference between men and women (marginal effect for female: $-0.057, p$-value $=0.640$ ) while "Tournament score" is significant and has a negative sign as one would expect (marginal effect: $-0.033, p$-value $=0.016$ ).

Table 1 - Determinants of tournament-entry decision (task 3)

\begin{tabular}{lcccccc}
\hline \hline \multirow{2}{*}{ Female } & $(1)$ & $(2)$ & $(3)$ & $(4)$ & $(5)$ & $(6)$ \\
Tournament score & $0.168^{* *}$ & $0.262^{* *}$ & 0.071 & & & \\
& $(0.079)$ & $(0.103)$ & $(0.086)$ & & & \\
Tournament - Piece rate score & $0.022^{*}$ & $0.039^{*}$ & 0.011 & 0.013 & 0.044 & 0.008 \\
& $(0.011)$ & $(0.022)$ & $(0.016)$ & $(0.009)$ & $(0.028)$ & $(0.011)$ \\
Guess other's score & -0.006 & -0.019 & -0.003 & -0.001 & -0.024 & $0.013^{*}$ \\
& $(0.014)$ & $(0.028)$ & $(0.015)$ & $(0.013)$ & $(0.028)$ & $(0.007)$ \\
Risk tolerance & $-0.185^{* *}$ & -0.036 & $-0.352^{* * *}$ & $-0.193^{* *}$ & $-0.204^{*}$ & -0.204 \\
\multirow{4}{*}{ Single-sex group } & $(0.084)$ & $(0.090)$ & $(0.088)$ & $(0.084)$ & $(0.118)$ & $(0.146)$ \\
& 0.029 & 0.027 & 0.026 & 0.027 & 0.001 & $0.067^{*}$ \\
\multicolumn{1}{c}{ Observations } & $(0.022)$ & $(0.030)$ & $(0.034)$ & $(0.020)$ & $(0.026)$ & $(0.038)$ \\
& & & & -0.048 & 0.035 & $-0.126^{* * *}$ \\
\multicolumn{1}{c}{ Notes } & 147 & 82 & 65 & 147 & 81 & 66 \\
& All & Single- & Mixed- & All & Women & Men \\
& obs. & sex only & sex only & obs. & only & only \\
\hline \hline
\end{tabular}

Probit regression; the dependent variable takes the value of 1 if the subject selected the tournament in task 3; entries are marginal effects estimated at the mean; robust standard errors in parentheses; the greyareas highlight coefficients related to our main variables of interest; 'Guess other's score' is a dummy variable taking the value 1 if a subject believes the other group members will solve correctly more additions on average; 'Risk tolerance' takes values between 1 to 7 where 1 indicates least agreement with the statement 'I am generally a person who is fully prepared to take risks' and 7 indicates most agreement. ${ }^{* * *} p<0.01, * * p<0.05, * p<0.1$

\footnotetext{
${ }^{12}$ In order to test the relative importance of each of these factors, we also ran regressions in which each of the factors is used separately. The female dummy becomes significant only when we control for Tournament score.
} 
Next, we investigate how the propensity to compete depends on the composition of groups. It is important to note that, unlike in Gneezy et al. (2003), the composition of groups does not affect performance in either task 1 (single-sex: 10.95, mixed-sex: $11.50 ; p$-value=0.370, MWU test, $N=141$ ) or task 2 (single-sex: 11.15 , mixed-sex: $12.66, p$-value $=0.123$ ), although in task 3 performance is higher in mixed-sex groups (single-sex: 13.76, mixed-sex: 15.63, $p$ value $=0.0527$ ). If we consider men and women separately, we find no differences across tasks for any of the comparisons ( $p$-value $>0.15$, MWU test), except for men who compete more in the third task in mixed-sex groups (single-sex: 15.00, mixed-sex: 17.63, $p$-value=0.053). We also do not find differences in beliefs about others' performance in single- vs. mixed-sex groups (Women: $p$-value $=0.706$; Men: $p$-value $=0.789$ ).

Result 2: While women are as likely to select to compete in the single-and the mixed-sex tournament, men are more likely to compete in mixed-than in single-sex groups.

SUPPORT: Women select the tournament $54.3 \%$ of the time in both single- and mixed-sex groups $\left(p\right.$-value $=0.996, \chi^{2}$ test, $\left.N=81\right)$. Men are more likely to select the tournament when placed in mixed groups (56.7 vs. $44.4 \%$ ), but the difference is not significant ( $p$-value $=0.333$,

$\chi^{2}$ test, $N=66$ ). This however changes once we control for other factors that were shown above to influence the decision to compete. While women are as likely to compete in single- and mixed-sex groups (model 5 in Table 1), men are significantly more likely to compete in mixedsex groups (model 6). These findings are thus in line with those in Datta Gupta et al. (2013). Overall, individuals are as likely to compete in single- and mixed-sex groups (model 4).

\section{Do women compete too much?}

The fact that women are as likely to select into competition in mixed groups despite men's higher scores suggests that they may be competing too much for their own good. To explore this possibility we performed a simulation in which we randomly created 10,000 4-person groups from our sample. The simulation allows us to estimate the probability that a person with a given score in task 3 wins the tournament (for details, see OSM). If participants are riskneutral money maximizers, they should enter into competition in task 3 only if they believe their chances of winning are at least $25 \%$.

Figure 1 graphs the probability of winning depending on one's score, separately for each condition. A quick look at the figure shows that it is harder to win as the fraction of men in a group increases. In single-sex groups, a woman with a score of 12 has a $26 \%$ chance to win the tournament. The situation is very different for men who need a score of 18 or more to have an 
above- $25 \%$ chance to win in single-sex groups. The fact that even someone with a score of 27 (i.e., 2.3 times the average in women-only groups, and 1.7 that in men-only groups) has only a $76.3 \%$ chance of winning indicates the presence of a few 'star' performers among men.

The existence of star performers among men implies that women should be less willing to compete in mixed-sex groups (if their goal is to maximize their earnings). For example, a woman with a score of 12 who had a $26 \%$ chance of winning in a women-only group would have less than $11 \%$ chance of winning the mixed-sex tournament. The opposite applies to men who have a higher chance of winning in mixed- than in single-sex groups. Whereas men need a score of 18 or more to have a chance above $25 \%$ of winning in single-sex groups, in mixed-sex groups, they need a score of 15. The reason is that, in mixed groups, the chance of encountering another male star performer is lower than in men-only groups.

Figure 1 - Cumulative distribution function of winning

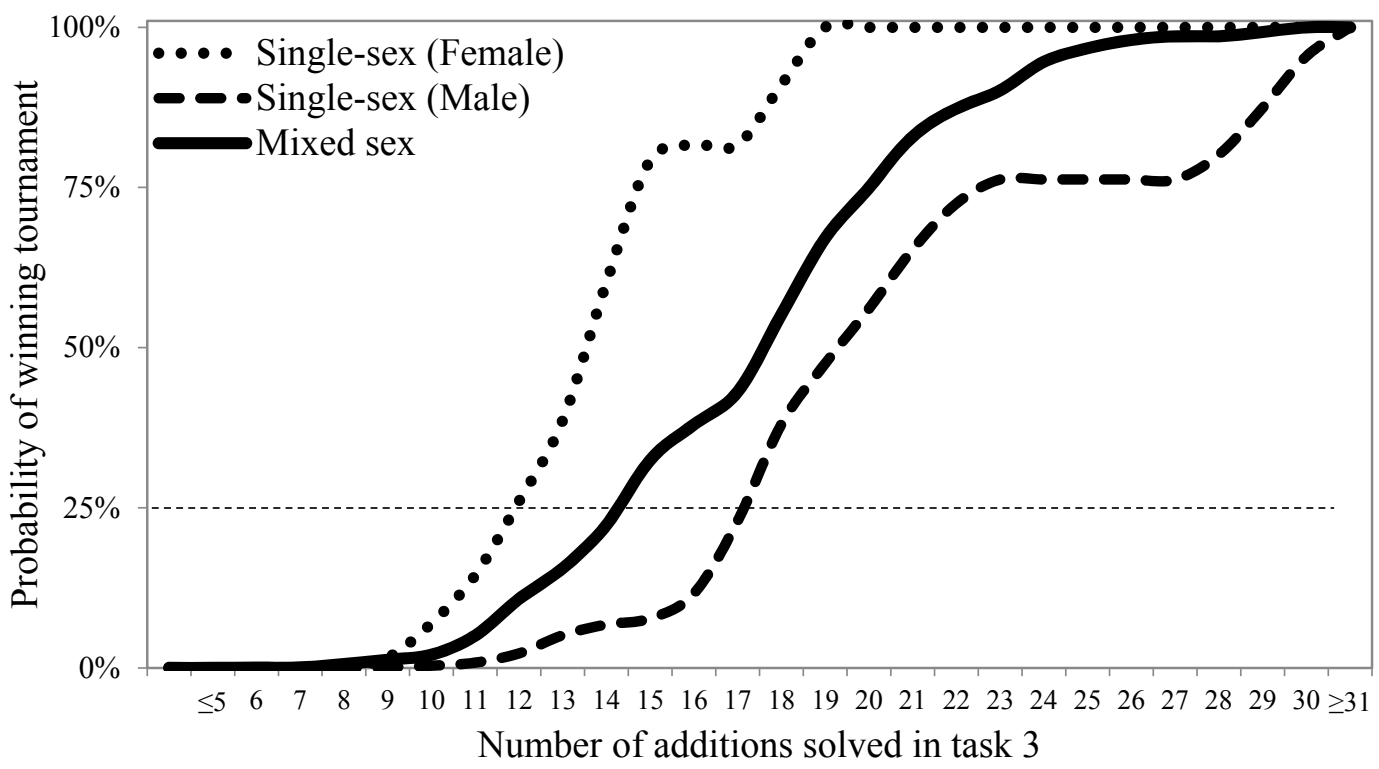

How often should men and women compete? Panel (A) in Table 2 illustrates that, across conditions, women and men should choose to compete about half of the time $(46.9 \%$ and $48.5 \%$, respectively) assuming their goal is to maximize their earnings and that the probability distribution of winning is known. A comparison with Panel (B) shows that this is close to what happened in the experiment, though women compete a bit more (see also Result 1).

The main insight from Table 2 (Panel A) is that both men and women should have been less willing to compete as the fraction of men in their group increases, (i.e., men in single-sex groups and women in mixed-sex groups should compete less). Although men are less likely to 
compete as the fraction of other male competitors increases (see also Result 2), a comparison with Panel (B) illustrates that they still tend to compete too much in single-sex groups and too little in mixed-sex groups. Women on the other hand are as likely to compete in single-and mixed-sex groups (see also Result 2). Panel (B) shows that this is driven mainly by women competing too much in mixed-sex groups.

Panels (C) and (D) show that men are more likely to under-enter in men-only (single-sex) groups (i.e., not enter when they should enter), and women are more likely to over-enter in mixed-sex groups (i.e., not enter when they should not enter). Although on aggregate women are more likely to over-enter and less likely to under-enter, i.e., the opposite than in NV, the difference is far from being statistically significant.

Table 2 - Who competes too much and when?

(A) \% that should compete

\begin{tabular}{ccc}
\hline \hline & Female & Male \\
\hline Single & $60.9 \%$ & $27.8 \%$ \\
Mixed & $28.6 \%$ & $73.3 \%$ \\
\hline Total & $46.9 \%$ & $48.5 \%$ \\
\hline \hline
\end{tabular}

(C) \% that should but don't compete (underentry)

\begin{tabular}{ccc}
\hline \hline & Female & Male \\
\hline Single & $35.7 \%$ & $50.0 \%$ \\
Mixed & $40.0 \%$ & $40.9 \%$ \\
\hline Total & $36.8 \%$ & $43.8 \%$ \\
\hline \hline
\end{tabular}

(B) \% that competes

\begin{tabular}{ccc}
\hline & Female & Male \\
\hline Single & $54.3 \%$ & $44.4 \%$ \\
Mixed & $54.3 \%$ & $56.7 \%$ \\
\hline Total & $54.3 \%$ & $50.0 \%$ \\
\hline \hline
\end{tabular}

(D) \% that shouldn't but do compete (overentry)

\begin{tabular}{ccc}
\hline \hline & Female & Male \\
\hline Single & $38.9 \%$ & $42.3 \%$ \\
Mixed & $48.0 \%$ & $50.0 \%$ \\
\hline Total & $44.2 \%$ & $44.1 \%$ \\
\hline
\end{tabular}

\section{Conclusion}

We have found evidence women do not shy away from competition in a sample of young UAE nationals. This is the case whether they are competing exclusively against other women or in mixed groups with men. To our knowledge, this is the first study employing a university sample in which women are not found to compete less than men (see Table A1). In fact, with the exception of the Indian matrilineal sample in Gneezy et al. (2009), it is the only evidence adult women are not less willing to compete than men. In light of previous evidence concerning the differences in competitiveness in patriarchal societies, one possible explanation is that the policies to empower women have been successful at changing attitudes towards competition among young adults. In line with this are the findings from a 2016 survey of undergraduates across the world by Accenture showing that more female students aspire to 
senior leadership positions (67\%) than men (62\%) in the UAE, compared to $41 \%$ and $51 \%$ respectively for the entire sample (Khaleej Times, 2017).

Lest we are misinterpreted, two important qualifiers are in order. First, we do not claim that a top-down change in institutions will always lead to a reduction in the gender gap in competitiveness (cf. Zhang, in press). In the UAE, the introduction of policies to empower women in the past decade followed a prolonged period of interaction with Western migrants. Therefore, the institutional change may partly reflect an overall change in social attitudes towards women. Second, we note that, at this point in time, our interpretation of our findings is only a conjecture as the data do not permit us to rule out alternative explanations. One factor that could be contributing to the lack of a gender gap, for example, is the separate campuses for men and women, even though as mentioned the evidence on the impact of single-sex schooling on competitiveness is mixed (Booth and Nolen 2012, Lee et al. 2014). In addition, although there is no problem with self-selection into our experiment, we cannot rule out the possibility that our findings are affected by selection into higher education. Across the UAE, Emirati women are much more likely to attend university than men who have ready access to wellpaying jobs in the public sector such as those in military and police. Having said this, it is interesting to note that the percentage of men choosing to compete in our experiment is well within the range of that observed in previous studies (see Table A1), whereas the percentage of women choosing to compete in our sample is the highest observed so far. Related to this, we cannot rule out the possibility that self-selection into lab experiments in previous studies is partly responsible for the different findings obtained. It would be interesting if future studies were to explore relative attitudes towards competition in other societies in which traditional values are at odds with modern institutions as they could help shed light on the impact of policies for empowering women on competitiveness.

\section{References}

Al Fahim, M.A.J. (2011). From Rags to Riches - A Story of Abu Dhabi. Macarem LLC Books.

Almås, I., Cappelen, A.W., Salvanes, K.G., Sørensen, E, Ø., \& Tungodden, B. (2016). Willingness to compete: Family matters. Management Science 62(8), 2149-2162.

Apicella, C., Demiral, E. E., \& Mollerstrom, J. (in press). No gender difference in willingness to compete when competing against self. American Economic Review, Papers and Proceedings.

Apicella, C., \& Dreber, A. (2015). Sex differences in competitiveness: Hunter-gatherer women and girls compete less in gender-neutral and male-centric tasks. Adaptive Human Behavior and Physiology, 1(3), 247-269. 
Andersen, S., Ertac, S., Gneezy, U., List, J.A., \& Maximiano, S. (2013). Gender, competitiveness, and socialization at a young age: Evidence from a matrilineal and a patriarchal society. Review of Economics and Statistics, 95(4), 1438-1443.

Balafoutas, L., Kerschbamer, R., \& Sutter, M. (2012). Distributional preferences and competitive behavior. Journal of Economic Behavior \& Organization, 83(1), 125-135.

Balafoutas, L., \& Sutter, M. (2012). Affirmative action policies promote women and do not harm efficiency in the laboratory. Science, 335(6068), 579-582.

Banerjee, R. Datta Gupta, N., \& Villeval, M.C. (in press). The spillover effects of affirmative action on competitiveness and unethical behavior. European Economic Review.

Berlin, N. \& Dargnies, M.P. (2016). Gender differences in reaction to feedback and willingness to compete. Journal of Economic Behavior and Organization, 130, 320-336.

Bönte, W., Procher, V., \& Urbig, D., (in press). Gender differences in selection into selfcompetition. Applied Economics Letters.

Booth, A. \& Nolen, P. (2012). Choosing to compete: How different are girls and boys? Journal of Economic Behavior \& Organization, 81(2), 542-555.

Buser, T., Dreber A. \& Möllerström, J. (2017). The impact of stress on tournament entry. Experimental Economics 20(2), 506-530.

Buser, T., Gerhards, L., \& van der Weele, J. (in press). Responsiveness to feedback as a personal trait. Journal of Risk and Uncertainty.

Buser, T., Niederle, M., \& Oosterbeek, H. (2014). Gender, competitiveness, and career choices. The Quarterly Journal of Economics 129(3), 1409-1447.

Buser, T., Peter, N., \& Wolter S.C. (2017). Gender, competitiveness, and study choices in high school: Evidence from Switzerland. American Economic Review, 107(5), 125-130.

Cadsby, C. B., Servátka, M., \& Song, F. (2013). How competitive are female professionals? A tale of identity conflict. Journal of Economic Behavior \& Organization, 92, 284-303.

Cárdenas, J. C., Dreber, A., Von Essen, E., \& Ranehill, E. (2012). Gender differences in competitiveness and risk taking: Comparing children in Colombia and Sweden. Journal of Economic Behavior \& Organization, 83(1), 11-23.

Cassar, A., Wordofa, F., \& Zhang, Y. J. (2016). Competing for the benefit of offspring eliminates the gender gap in competitiveness. Proceedings of the National Academy of Sciences, 113(19), 5201-5205.

Chen, D. L., Schonger, M., \& Wickens, C. (2016). oTree - An open-source platform for laboratory, online, and field experiments. Journal of Behavioral and Experimental Finance, 9, 88-97.

Dargnies, M. P. (2012). Men too sometimes shy away from competition: The case of team competition. Management Science, 58(11) 1982 - 2000.

Datta Gupta, N., Poulsen, A., \& Villeval, M.C. (2013). Gender matching and competitiveness: Experimental evidence. Economic Inquiry, 51(1), 816-835. 
Dreber, A. von Essen, E., \& Ranehill, E. (2014). Gender and competition in adolescence: task matters. Experimental Economics, 17(1), 154-172.1

Dohmen, T., Falk, A., Huffman, D., Sunde, U., Schupp, J., \& Wagner, G.G. (2011). Individual risk attitudes: Measurement, determinants, and behavioral consequences. Journal of the European Economic Association, 9(3), 522-550.

Gneezy, U., Leonard, K.L. \& List, J. A. (2009). Gender differences in competition: Evidence from a matrilineal and a patriarchal society. Econometrica, 77(5), 1637-1664.

Gneezy, U., Niederle, M. \& Rustichini, A. (2003). Performance in competitive environments: Gender differences. The Quarterly Journal of Economics, 118(3), 1049-1074.

Halko, M. L., \& Sääksvuori, L. (2017). Competitive behavior, stress, and gender. Journal of Economic Behavior \& Organization, 141, 96-109.

Healy, A. \& Pate, J. (2011). Can teams help to close the gender competition gap? The Economic Journal, 121(555), 1192-1204.

Kamas, L. \& Preston, A. (2012). The importance of being confident; gender, career choice, and willingness to compete. Journal of Economic Behavior \& Organization, 83(1), 82-97.

Khaleej Times (2017). Gender pay gap could close 100 years earlier than predicted'. Khaleej Times, (Apr. 4) Retrieved Aug. 22, 2017 from https://www.pressreader.com/uae/khaleejtimes/20170404/281779923972373.

Khachatryan, K., Dreber, A., Von Essen, E., \& Ranehill, E. (2015). Gender and preferences at a young age: Evidence from Armenia. Journal of Economic Behavior \& Organization, 118, 318-332.

Lee, S., Niederle, M., \& Kang, N. (2014). Do single-sex schools make girls more competitive? Economics Letters 124(3), 474-477.

Lönnqvist, J. E., Verkasalo, M., Walkowitz, G. \& Wichardt, P.C. (2015). Measuring individual risk attitudes in the lab: Task or ask? An empirical comparison. Journal of Economic Behavior \& Organization, 119, 254-266.

Mayr, U., Wozniak, D., Davidson, C., Kuhns, D., \& Harbaugh, W.T. (2012). Competitiveness across the life span: The feisty fifties," Psychology and Aging, 27(2), 278-285.

Moghadam, V. M. (2004). Patriarchy in transition: Women and the changing family in the Middle East. Journal of Comparative Family Studies. 35(2), 137-162.

Müller, J., Schwieren, C. (2012). Can personality explain what is underlying women's unwillingness to compete? Journal of Economic Psychology, 33(3), 448-460.

Niederle, M. (2016). Gender. In the Handbook of Experimental Economics, second edition, Eds. John Kagel and Alvin E. Roth, Princeton University Press.

Niederle, M. \& Vesterlund, L. (2007). Do women shy away from competition? Do men compete too much? The Quarterly Journal of Economics, 122(3), 1067-1101.

Niederle, M., Segal, C., \& Vesterlund, L. (2013). How costly is diversity? Affirmative action in light of gender differences in competitiveness. Management Science, 59(1), 1-16. 
Pennington, R. (2016). Working women in UAE supported by husbands, but hindered by culture, survey finds, The National, (Dec. 26). Retrieved Aug. 22, 2017 from https://www.thenational.ae/uae/working-women-in-uae-supported-by-husbands-buthindered-by-culture-survey-finds-1.173630.

Price, C. R. (2012). Gender, competition, and managerial decisions. Management Science, 58(1), 114-122.

Reuben, E., Sapienza, P. \& Zingales, L. (2015). Taste for competition and the gender gap among young business professionals (No. w21695). National Bureau of Economic Research.

Reuben, E., Wiswall, M. \& Zafar, B. (2017). Preferences and biases in educational choices and labor market expectations: Shrinking the black box of gender. Economic Journal 127: 2153-2186.

Samak, Anya C. (2013). Is there a gender gap in preschoolers' competitiveness? An experiment in the US. Journal of Economic Behavior \& Organization, 92, 22-31.

Shurchkov, O. (2012). Under pressure: gender differences in output quality and quantity under competition and time constraints. Journal of the European Economic Association, 10(5), 1189-1213.

Sutter, M., Glätzle-Rützler, D., Balafoutas, L., Czermak, S. (2016), Canceling out early age gender differences in competition - an analysis of policy interventions. Experimental Economics, 19(2), 412-432.

Sutter, M. \& Glätzle-Rützler D. (2015). Gender differences in the willingness to compete emerge early in life and persist. Management Science. 61(10), 2339-2354.

UAE Government. (2017). Women. Retrieved Aug. 15, 2017, from https://government.ae/en/information-and-services/social-affairs/women.

World Economic Forum. (2016). The Global Gender Gap Report. Retrieved Aug. 22, 2017, from http://reports.weforum.org/global-gender-gap-report-2016.

Wozniak, D., Harbaugh, W.T. \& Mayr, U. (2014). The menstrual cycle and performance feedback alter gender differences in competitive choices. Journal of Labor Economics, 32(1), 161-198.

Zhang, Y. J. (in press). Culture, institutions, and the gender gap in competitive inclination: evidence from the communist experiment in china. Economic Journal

Zhong, S. Shalev, I. Koh, D., Ebstein, R.P., \& Chew, S. H. (in press). Competitiveness and stress. International Economic Review. 


\section{APPENDIX}

Table A1 - List of published or forthcoming studies using the Niederle-Vesterlund (2007) paradigm

(A) Studies using university students

\begin{tabular}{|c|c|c|c|c|c|}
\hline \multirow{2}{*}{ Study } & \multirow{2}{*}{ Country } & \multirow{2}{*}{ Task } & \multicolumn{2}{|c|}{ \% selecting competition } & \multirow{2}{*}{ Sample size } \\
\hline & & & Male & Female & \\
\hline Niederle \& Vesterlund (2007) & USA & Addition & $73 \%$ & $35 \%$ & $40 \mathrm{M}, 40 \mathrm{~F}$ \\
\hline Healy and Pate (2011) & USA & Addition & $81 \%$ & $28 \%$ & $96 \mathrm{M}, 96 \mathrm{~F}$ \\
\hline Balafoutas \& Sutter (2012) & Austria & Addition & $64 \%$ & $30 \%$ & $36 \mathrm{M}, 36 \mathrm{~F}$ \\
\hline Balafoutas et al. (2012) & Austria & Addition & $59 \%$ & $31 \%$ & $65 \mathrm{M}, 67 \mathrm{~F}$ \\
\hline Dargnies (2012) & France & Addition & $85 \%$ & $51 \%$ & $39 \mathrm{M}, 37 \mathrm{~F}$ \\
\hline Kamas and Preston (2012) & USA & Addition & $41 \%$ & $23 \%$ & $156 \mathrm{M}, 154 \mathrm{~F}$ \\
\hline Mueller and Schwieren (2012) & Germany & Addition & $42 \%$ & $26 \%$ & $57 \mathrm{M}, 70 \mathrm{~F}$ \\
\hline Price $(2012)$ & USA & Addition & $66 \%$ & $49 \%$ & $160 \mathrm{M}, 150 \mathrm{~F}$ \\
\hline \multirow{2}{*}{ Shurchkov (2012) } & \multirow{2}{*}{ USA } & Verbal & $39 \%$ & $30 \%$ & $74 \mathrm{M}, 54 \mathrm{~F}$ \\
\hline & & Math puzzles & $44 \%$ & $19 \%$ & $42 \mathrm{M}, 42 \mathrm{~F}$ \\
\hline Cadsby et al. (2013) & Canada & Addition & $36 \%$ & $9 \%$ & $66 \mathrm{M}, 66 \mathrm{~F}$ \\
\hline Datta Gupta et al. (2013) & France & Mazes & $60 \%$ & $34 \%$ & $50 \mathrm{M}, 50 \mathrm{~F}$ \\
\hline Niederle et al. (2013) & USA & Addition & $74 \%$ & $31 \%$ & $42 \mathrm{M}, 42 \mathrm{~F}$ \\
\hline \multirow{2}{*}{ Wozniak et al. (2014) } & \multirow{2}{*}{ USA } & Addition & $54 \%$ & $31 \%$ & $64 \mathrm{M}, 64 \mathrm{~F}^{\S}$ \\
\hline & & Verbal & $50 \%$ & $30 \%$ & $64 \mathrm{M}, 64 \mathrm{~F}^{\S}$ \\
\hline Berlin and Dargnies (2016) & France & Addition & $63 \%$ & $35 \%$ & $114 \mathrm{M}, 114 \mathrm{~F}$ \\
\hline Buser et al. (2017) & USA & Addition & $52 \%$ & $28 \%$ & $50 \mathrm{M}, 54 \mathrm{~F}$ \\
\hline Reuben et al. (2017) & USA & Addition & $54 \%$ & $27 \%$ & $89 \mathrm{M}, 168 \mathrm{~F}$ \\
\hline Halko and Sääksvuori (2017) & Finland & Addition & $74 \%$ & $54 \%$ & $40 \mathrm{M}, 40 \mathrm{~F}$ \\
\hline Apicella et al. (in press) & USA & Addition & $58 \%$ & $38 \%$ & $52 \mathrm{M}, 48 \mathrm{~F}$ \\
\hline Banerjee et al. (in press) & India & Memory task & $22 \%$ & $16 \%$ & $88 \mathrm{M}, 80 \mathrm{~F}^{\dagger}$ \\
\hline Buser et al. (in press) & Denmark & Mix & $42 \%$ & $26 \%$ & $137 \mathrm{M}, 160 \mathrm{~F}^{\dagger}$ \\
\hline Zhong et al. (in press) & Singapore & Addition & $49 \%$ & $25 \%$ & $98 \mathrm{M}, 99 \mathrm{~F}$ \\
\hline Dariel et al. (this study) & UAE & Addition & $50 \%$ & $54 \%$ & $66 \mathrm{M}, 81 \mathrm{~F}$ \\
\hline
\end{tabular}

(B) Studies using other adults (i.e., not university students)

\begin{tabular}{|c|c|c|c|c|c|}
\hline \multirow{2}{*}{ Study } & \multirow{2}{*}{ Country } & \multirow{2}{*}{ Task } & \multicolumn{2}{|c|}{ \% selecting competition } & \multirow{2}{*}{ Sample size } \\
\hline & & & Male & Female & \\
\hline \multirow{2}{*}{ Gneezy et al. (2009) } & Tanzania (patriarchal) & Bucket toss & $50 \%$ & $26 \%$ & $40 \mathrm{M}, 34 \mathrm{~F}$ \\
\hline & India (matrilineal) & Bucket toss & $39 \%$ & $54 \%$ & $40 \mathrm{M}, 34 \mathrm{~F}$ \\
\hline Mayr et al. (2012) & USA & Addition & $56 \%$ & $36 \%$ & $281 \mathrm{M}, 262 \mathrm{~F}$ \\
\hline \multirow{3}{*}{ Apicella et al. (2015) } & \multirow{3}{*}{ Tanzania } & Skipping rope & $45 \%$ & $30 \%$ & $102 \mathrm{M}, 89 \mathrm{~F}$ \\
\hline & & Bead collection & $52 \%$ & $37 \%$ & $50 \mathrm{M}, 38 \mathrm{~F}$ \\
\hline & & Handgrip strength & $67 \%$ & $29 \%$ & $39 \mathrm{M}, 31 \mathrm{~F}$ \\
\hline Cassar et al. (2016) & China & Addition & $36 \%$ & $26 \%$ & $173 \mathrm{M}, 185 \mathrm{~F}$ \\
\hline Bönte et al. (in press) & Germany & Math & $56 \%$ & $45 \%$ & $101 \mathrm{M}, 124 \mathrm{~F}$ \\
\hline
\end{tabular}

\section{[Continued on next page]}


(C) Studies using only children or pre-university students

\begin{tabular}{|c|c|c|c|c|c|}
\hline \multirow{2}{*}{ Study } & \multirow{2}{*}{ Country } & \multirow{2}{*}{ Task } & \multicolumn{2}{|c|}{ \% selecting competition } & \multirow{2}{*}{ Sample size } \\
\hline & & & Male & Female & \\
\hline \multirow{4}{*}{ Cardenas et al. (2012) } & \multirow{2}{*}{ Sweden } & Math search & $44 \%$ & $19 \%$ & $158 \mathrm{M}, 146 \mathrm{~F}$ \\
\hline & & Word search & $39 \%$ & $27 \%$ & $159 \mathrm{M}, 146 \mathrm{~F}$ \\
\hline & \multirow{2}{*}{ Colombia } & Math search & $35 \%$ & $32 \%$ & $163 \mathrm{M}, 152 \mathrm{~F}$ \\
\hline & & Word search & $26 \%$ & $29 \%$ & $164 \mathrm{M}, 152 \mathrm{~F}$ \\
\hline \multirow{2}{*}{ Andersen et al. (2013) } & India (matrilineal) & Bucket toss & $52 \%$ & $49 \%$ & $96 \mathrm{M}, 76 \mathrm{~F}$ \\
\hline & India (patriarchal) & Bucket toss & $51 \%$ & $39 \%$ & $71 \mathrm{M}, 75 \mathrm{~F}$ \\
\hline Samak (2013) & USA & 'Fishing' task & $77 \%$ & $83 \%$ & $60 \mathrm{M}, 63 \mathrm{~F}$ \\
\hline Buser et al. (2014) & Netherlands & Addition & $49 \%$ & $23 \%$ & $178 \mathrm{M}, 184 \mathrm{~F}$ \\
\hline \multirow{2}{*}{ Dreber et al. (2014) } & \multirow{2}{*}{ Sweden } & Addition & $36 \%$ & $17 \%$ & $108 \mathrm{M}, 108 \mathrm{~F}$ \\
\hline & & Word search & $33 \%$ & $28 \%$ & $108 \mathrm{M}, 108 \mathrm{~F}$ \\
\hline Lee et al. (2014) & South Korea & Addition & $30 \%$ & $22 \%$ & $254 \mathrm{M}, 386 \mathrm{~F}$ \\
\hline Sutter \& Rützler (2015) & Austria & Addition & $40 \%$ & $19 \%$ & $298 \mathrm{M}, 419 \mathrm{~F}$ \\
\hline \multirow{2}{*}{ Khachatryan et al. (2015) } & \multirow{2}{*}{ Armenia } & Addition & $54 \%$ & $52 \%$ & $428 \mathrm{M}, 396 \mathrm{~F}^{\S}$ \\
\hline & & Word search & $57 \%$ & $56 \%$ & $428 \mathrm{M}, 396 \mathrm{~F}^{\S}$ \\
\hline Sutter et al. (2016) & Austria & Addition & $44 \%$ & $21 \%$ & $123 \mathrm{M}, 123 \mathrm{~F}$ \\
\hline Almås et al. (2016) & Norway & Addition & $52 \%$ & $32 \%$ & $250 \mathrm{M}, 233 \mathrm{~F}$ \\
\hline Buser et al. (2017) & Switzerland & Addition & $68 \%$ & $51 \%$ & $90 \mathrm{M}, 159 \mathrm{~F}$ \\
\hline \multirow{3}{*}{ Zhang et al. (in press) } & China (Han) & Addition & $63 \%$ & $48 \%$ & $48 \mathrm{M}, 48 \mathrm{~F}^{\dagger}$ \\
\hline & China $(\mathrm{Yi})$ & Addition & $60 \%$ & $38 \%$ & $48 \mathrm{M}, 48 \mathrm{~F}^{\dagger}$ \\
\hline & China (Mosuo) & Addition & $75 \%$ & $48 \%$ & $40 \mathrm{M}, 40 \mathrm{~F}^{\dagger}$ \\
\hline
\end{tabular}

$\S$ These studies employ a within-subject design.

${ }^{\dagger}$ The statistics for these studies are not in the published paper, but were reported to us by the authors.

Notes: For a detailed discussion of how Table A1 was compiled see the OSM. In brief, Table A1 includes only studies following closely the setting of NV and which were either published or forthcoming as of November 5, 2017; when studies include treatments that differ considerably from $\mathrm{NV}$, for comparability, we report statistics only from the treatments which most closely resemble the NV setting. The table omits the study of Booth and Nolen (2012) as it does not report genderlevel entries. The authors use a sample of 260 pre-university students in the UK as subjects who solve mazes and find women are $27 \%$ less likely to compete than men. 


\section{Online Supplementary Material}

Emirati women do not shy away from competition:

Evidence from a patriarchal society in transition

By Aurelie Dariel, Curtis Kephart, Nikos Nikiforakis and Christina Zenker 
The OSM includes the following:

1. Notes on the compilation of Table A1

2. Experimental instructions

3. Information concerning experimenters present during the experiment

4. Information concerning relative tournament performance in task 3

5. Information concerning the simulation analysis 


\section{Literature review}

Table A1 provides an overview of the existing studies in the literature concerning gender differences in competitiveness, and their findings. We restrict our review to published studies using the Niederle and Vesterlund (2007) paradigm in which participants are asked to choose between a piecerate and a tournament, even if the task subjects had to complete (e.g., addition, verbal) was different to that in the original study. For purposes of comparability, studies exploring whether men and women behave differently when forced into competition vis-à-vis when forced to perform alone (i.e., when participants do not make a choice between tournament and piece-rate, e.g., Gneezy et al. 2003, Gneezy and Rustichini 2004, Dreber et al. 2011) are not included; the same applies for studies in which individuals vote as a group for which payment scheme to use (Balafoutas et al. 2016) or in which the return from winning the tournament is fixed rather than a function of one's performance (e.g., Cason et al. 2010). In contrast, we include studies in which

All efforts were made to include all studies meeting the inclusion criteria. After our initial search, on November $1^{\text {st }}$ 2017, we sent emails to esa-announce@googlegroups.com and esadiscuss@googlegroups.com asking colleagues to inform us by November $5^{\text {th }} 2017$, whether they had a study they believed ought to be included in Table A1, but we might have missed. These email addresses are used to reach the entire ESA community and it is in these addresses where job openings or conferences are announced. We hope that the list in Table A1 presents all published studies on the topic.

Table A1 gives a sense of the replicability of the Niederle and Vesterlund findings. Again for purposes of comparability, when the experiment includes several treatments we report findings (and sample sizes) from the treatments most closely related to the set up in Nierdele and Vesterlund (2007). For instance, we report data only from the CTR treatment in Balafoutas and Sutter (2012) and Sutter et al. (2016), i.e., not from the affirmative-action treatments, only from the math-task treatment in Sutter and Glätzle-Rützler (2015), and the weak-prime treatment in Datta Gupta et al. (2013). We do not include the data from the Self-treatment and the online experiment (MTurk) in Apicella et al. (2017) as this was arguably a very different environment than that in any of the other studies. The same applies for the treatment in which subjects were rewarded with vouchers in Cassar et al. (2016), or competed in teams in Healy et al. (2011) and Dargnies (2012). For Songfa et al. (in press) we report only data from Experiment 2, as before making their choice of payment scheme in Experiment 1, subjects were given a 40-minute break to measure their stress response. For Banerjee et al. (in press), we report data communicated to us by the authors, from their Baseline treatment (T0).

The studies are divided into three categories depending on the sample: university students, adults (excluding university students), and pre-university students. Within these categories, the studies are presented in chronological order, based on the year of publication. 


\section{Experimental Instructions}

[Unless otherwise stated, the following instructions are from the single-sex group treatment.]

You are now taking part in an experiment. You will receive a transport and subsistence allowance which will depend on decisions made in the experiment, with a minimum allowance of $30 \mathrm{AED}$. It is therefore important that you read the instructions carefully as they explain how your decisions will affect the allowance you receive at the end of today's session.

You cannot use any electronic devices or communicate with others throughout the experiment. Violation of this rule will disqualify you from payment.

As you complete parts of the experiment you will receive a score expressed in "points". 1 point is equivalent to 2 AED. Your allowance will be paid in Dirhams (AED) in private at the end of the session. No one will be informed about your decisions in the experiment.

After the experiment, you will have the possibility of donating a percentage of your allowance to a charity. $^{13}$

In the experiment you will be asked to complete three different tasks. No task will take more than 3 minutes. At the end of the experiment one of the tasks will be randomly selected, and you will be paid based on your performance in that task.

Before each task you will receive specific instructions. These instructions will explain how you make decisions, and how your decisions and the decisions of other participants influence your allowance.

Before the experiment is over, you will be asked to fill out a questionnaire.

\section{Task 1 Instructions}

In this part of the experiment, you will be presented with a series of two two-digit numbers (for example, 11 and 22) which you will have to add (for example, $11+22=33$ ).

This part will last 3 minutes.

If Task 1 is the one randomly selected to determine the amount you receive as an allowance for participating in this experiment, then you will get 1 point for each correct answer. Your score will not decrease if you provide an incorrect answer.

\section{For each point, your allowance will increase by 2 AED. Remember that you will have the option to donate part of your allowance to charity.}

\footnotetext{
${ }^{13}$ As part of a larger project, we also varied whether subjects were told in advance that there would be an opportunity to donate to charity. We do not find any evidence that the announcement of the opportunity to give to charity has an effect on performance in the addition task or selection into tournament.
} 
You cannot use a calculator or your phone to solve these additions, but you are welcome to make use of the provided pen and paper.

After 3 minutes, the task will stop and you will receive a summary of the results.

Please raise your hand and alert an experimenter if you have any questions.

\section{Task 2 Instructions}

In this task, as in Task 1, you will have 3 minutes to calculate the correct sum of a series of two twodigit numbers. Your final score will depend on your performance relative to that of a group of other female students at Zayed University participating in this experiment under similar circumstances. ${ }^{14}$ Each group consists of four people. The three other members of your group will be randomly selected. You will never know the names of the other people in your group and they will never know your name or actions.

There are two possible outcomes if Task 2 is randomly selected to determine your allowance. If you are the individual who correctly solves the largest number of additions in your group, you will receive 4 points for each correct addition. If you are not this individual, you will receive zero points for this task.

For example, if you correctly completed 10 additions, and the three other members of your group completed 7, 8, and 9, then you will earn 40 points $(4 * 10)$ if Task 2 is selected at the end of the experiment. That is, $80 \mathrm{AED}$. In the event that more than one individual perform the same number of correct additions, and they are tied for the first place, a single player will be randomly chosen as the winner.

For each point, your allowance will increase by 2 AED. Remember that you will have the option to donate part of your allowance to charity. You will not be informed about whether or not you won or lost in this task until later in the experiment.

Please raise your hand and alert an experimenter if you have any questions.

\footnotetext{
${ }^{14}$ In the case of single-sex groups for men, this sentence was replaced with: "Your final score will depend on your performance relative to that of a group of other male students at Zayed University participating in this experiment under similar circumstances." In the case of mixed-sex groups, the sentence was: "Your final score will depend on your performance relative to that of a group of other male and female students at Zayed University participating in this experiment under similar circumstances."
} 


\section{Task 3 Instructions}

As in the previous tasks you will be given 3 minutes to calculate the correct sum of a series of two 2digit numbers.

Before we begin with the task, you will have to choose whether your allowance depends on your individual performance (as in Task 1) or your compared performance (as in Task 2).

If Task 3 is randomly selected to determine your allowance, then:

- If you choose individual performance you will receive 1 point per problem you solve correctly (as in Task 1).

- If you choose the compared performance your performance will be compared to that of the other three participants in your group in Task 2. If you are the individual who correctly solves the largest number of additions, you will receive 4 points for each correct addition. If you are not this individual, you will receive zero points in this task.

For each point, your allowance will increase by 2 AED. Remember that you will have the option to donate part of your allowance to charity.

When you are ready to start, click the next button.

\section{Performance Question}

Please answer the following

What do you think: The other members of your group solved correctly more or fewer additions than you in Task 2?

Probably more additions

Probably fewer additions 


\section{Information concerning experimenters present during the experiment}

There were always at least two experimenters in the room. While we took care to always have at least one male experimenter, in some sessions this was not possible, and both experimenters were female. We find no evidence of different behavior in these sessions in our analysis. We omit from our sample two female sessions with a total of 35 observations as their professor insisted on staying in the room.

\section{Information concerning relative tournament performance in task $\mathbf{3}$}

In the third task, participants had to choose between the piece rate and the tournament. After that, they perform the task one final time. Like in $\mathrm{NV}$, if they chose to compete, their score was compared to that of participants in the second task. Since the experiment utilized groups of four but we could not know in advance how many students will turn up in class, the software was coded such that an individual's score in task 2 or 3 was compared to that of three randomly drawn participants from all previous sessions.

\section{Information concerning the simulation analysis}

Given the uncertainty about the number of students who would show up for each class, as in Gneeezy et al. (2003), we decided not to inform explicitly participants about the likelihood of being matched with a man or a woman in mixed-sex groups. For the simulation, the likelihood that a man or woman in our sample is randomly selected reflects the ratio of men and women attending Zayed University. This is, $14.4 \%$ (709 men and 4202 women). This approach seems reasonable given that the information about

the relative fraction of men and women is public information and can be easily found online. Note however that our conclusions from the simulation are not sensitive to this assumption. We obtain the same conclusions qualitatively if we do not reweigh our sample.

\section{OSM references}

Balafoutas, L., Brent, D., \& Sutter, M. (2016). Affirmative action or just discrimination? A study on the endogenous emergence of quotas. Journal of Economic Behavior and Organization, 127: 87-98.

Cason, T.N. Masters, W.A., \& Sheremeta, R.M. (2010). Entry into winner-take-all and proportionalprize contests: An experimental study. Journal of Public Economics, 94 (9-10), 604-611.

Dreber, A., von Essen, E. \& Ranehill, E. (2011). Outrunning the Gender Gap-Boys and Girls Compete Equally. Experimental Economics, 14 (4), 567-582.

Gneezy, U., Leonard, K.L. \& List, J. A. (2009). Gender Differences in Competition: Evidence from a Matrilineal and a Patriarchal Society. Econometrica, 77 (5), 1637-1664.

Gneezy, U., Niederle, M. \& Rustichini, A. (2003). Performance in Competitive Environments: Gender Differences. Quarterly Journal of Economics, 118 (3), 1049-74. 